\title{
Application on Mind Map in College English Reading Teaching
}

\author{
Yan Wang \\ Teaching and Research Institute of Foreign Languages, Bohai University, Jinzhou, 121013, China \\ 964187193@qq.com
}

Keywords: mind map; college English; reading teaching; application; basic characteristics; teaching process

\begin{abstract}
Improve your reading ability is an important task of college English teaching. In view of the present problems in college English reading teaching, this paper based on the study of mind mapping offers a new thought and method for college English reading teaching. Mind mapping is a kind of method based on schema theory, take shape knowledge network system, can stimulate the students' reading motivation, make the students better understand and memory reading materials and cultivate the students' ability of information organization. The research content mainly includes the basic characteristics of the mind map, mind map making and mind map teaching process. Among them, the teaching process is the key content of mind mapping, to study the preparation before class, classroom teaching and after class to consolidate the basic method.
\end{abstract}

\section{Introduction}

College English teaching goal is to cultivate the students' English comprehensive application ability and reading teaching occupies very important position in college English teaching. Famous scholar Mr. Crook argues that put a lot of reading as the main means of English teaching. People learn by reading foreign information, reading teaching should not only teach language knowledge, but also to develop language skills. Less in the present college English teaching class under the background, content and tasks more heavy, comprehensively improve the students' listening, speaking, reading, writing and translating skills, such as the effective way is to increase the reading quantity, through contact with a large number of language materials, increase the intake of language, so as to enhance the language sense, enlarge vocabulary, abundant background knowledge, improve the flexibility and ability to use the language. In the process of college English reading teaching, the students with English language structure background culture does not understand and grasp the inaccurate or lead to deviation, or even if the article is not uncommon but vocabulary understanding of long sentences, all of these are because the schema in mind at work. Psychologists pointed out that reading is the readers' language knowledge and background knowledge interaction process of complex psychological language readers the original schema in mind will affect the understanding of the text and grasp.

Schema theory is organized around a certain theme of the representation and storage method based on the theory of knowledge. Modern schema theory is in the field of information science and computer science into the psychology, the psychology of human cognitive research developed after profound changes have taken place. Schema theory is a kind of knowledge about people were characterized, and how about knowledge representation in a characteristic way which is helpful for the application of knowledge theory [1]. According to the theory, the human brain in the preservation of all knowledge can be divided into unit, constitute a "block" and composition of the system. These units "block" and system is the schema. Studies of schemata, western scholars have suggested reading model and the text understanding model. The model has a widespread impact on improving the efficiency of reading comprehension, attaches great importance to by experts and scholars.

Schema main function is used to explain the process of people's understanding of objective things, and the comprehension is use schema to understand reading materials, the processing and evaluation process. Cognitive psychology, points out that understanding is the main mechanism, when the clues to activate the students reading materials in mind schemata, schema variables will be 
the information in the reading material in the concrete and make the students use schemata to assimilate new knowledge, or to change the old patterns, to accept the new knowledge. Mind map is a graphic method based on schema theory, learners in the process of using a mind map to knowledge learning, the integrated use of the function of the left and right hemispheres, subtly to comb and communication knowledge, and effectively organized in the form of visualization, the links between knowledge, reveals the connection between the knowledge points, form a knowledge network system, this form of cognitive schemata to facilitate understanding and memory, thus promotes the formation of long-term memory. Therefore, in reading teaching, proper use mind mapping, can not only play the role of knowledge understanding, memory and finishing, also can cultivate students' divergent thinking, is a good method of college English reading comprehension teaching.

\section{Basic Characteristics on Mind Map}

Mind map has four basic characteristics: the focus of the meaning clearly focused on the central figure; Branch from the central theme of the trunk as a graphic to radiation; Branch produced by a key graphics or write in the line of image on keywords, less important topic also expressed in the form of branch, attached to the higher levels of branches; Branches to form a connection node structure. Describe the characteristics of the mind map as a graphic, as shown in Fig. 1 [2]. This is a picture only two level structure of graphics, four main branches respectively corresponding to the four basic characteristics. Each feature elements decomposes as a supplement of the secondary branch. In order to vividly illustrate the box branch, in the figure increased the two branches of the box.

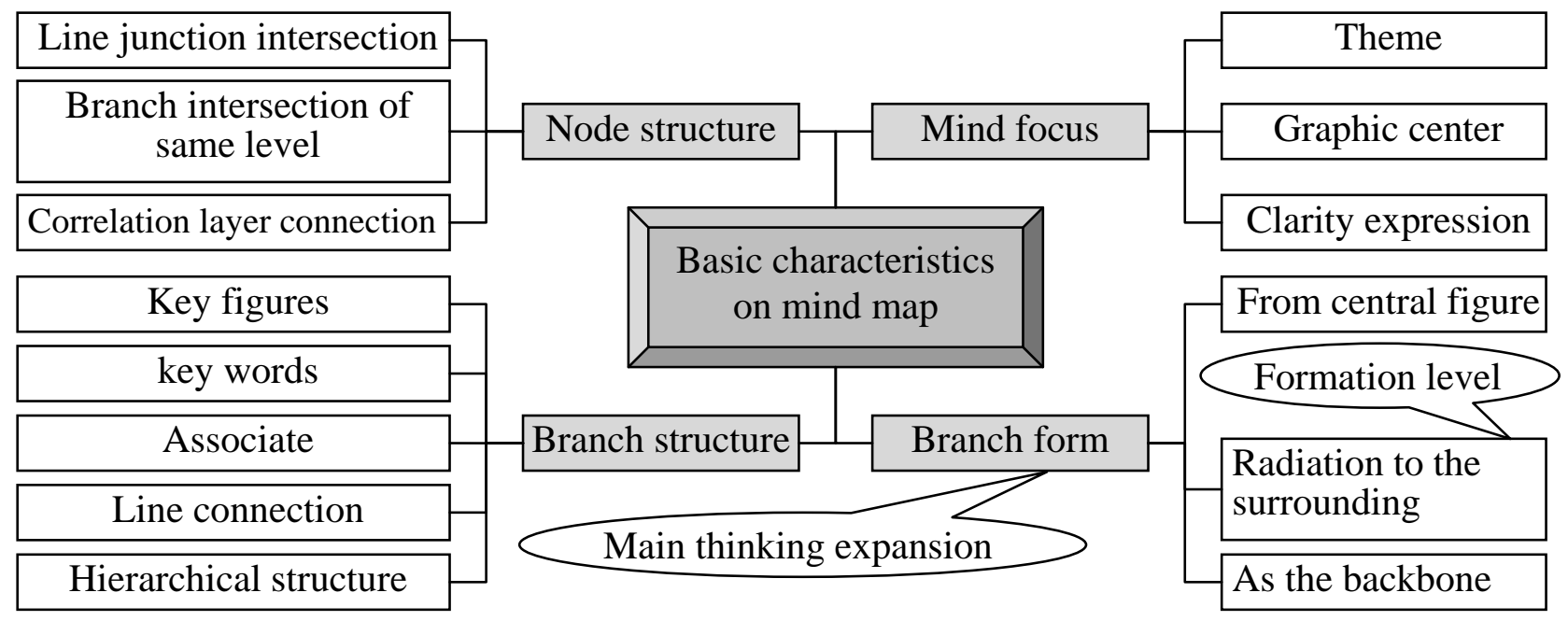

Fig. 1. Basic characteristics on mind map

\section{Mind Map Making}

The method of making the mind map has three types: one kind is hand-painted, and the second is to use Visio and Word common software, the third kind is the specialized software. This study draws a mind map using professional software.

MindMapper is a professional visual concept map implementation, for information management and processing workflow intelligence tool software, can through the intelligent drawing method using node and branch of the software system. MindMapper belongs to "mind map", "brain storm" type of software, the effect of such software is: put your head inside the chaotic, trivial idea connected to help the user to compose and eventually form a coherent, logical and mature thinking.

MindMapper before use must be installed in the computer, the installation process is as follows [3, 4]: download good MindMapper installation package; Double click on the install package line, click on the "Next" after the pop-up dialog box, on to the Next step; In the license agreement page 
check the "Yes" said agreed to accept the license agreement terms, jump the next step; In the installation type page, there are two options, "Typical" said Typical conventional installation, "Custom" said Custom installation, to choose and then click the "Next". In the jump out the window of the fill in the user information, including user name and the name of the company, click the "Next". Choose to install a computer position, click "Next" after confirmation. After the installation completed, click Finish to exit the setup wizard, in the window has an option "open MindMapper immediately," according to individual needs and tastes. MindMapper simple using method is as follows:

(1) From the system onion parody or press down the key combination "Ctrl + Shift + N", open a new document window, there are a lot of templates and examples for reference to choose.

(2) After enter a topic, if the input branch, can press the space, the system automatically add a new branch. Can also enter the content of the branch, the system automatically branch as a child is added to the theme.

(3) There are two ways that quick add more topics: one is to press "Shift + number n" key, the system automatically add n branches around the currently selected topic; Second, press "Ctrl + Space", the system pop-up window, in which you can input multiple lines of text, after the input, automatic branch added as a child on the currently selected theme.

(4) Quickly copy content from other program into the mind map as the theme. Also provides two ways: one is to press the "Insert" option to sign the copy in the automatic mode, the content of the selected with the mouse, automatically added as a sub branch of the current theme in mind mapping software. Second is to press the "F6" key to enter or exit the automatic replication mode.

(5) Floating theme, in mapping can enter any floating theme, central theme with the page can't contact. Can be used to insert "Float topic" the way into the. Or directly use the mouse to click on the background, you can enter floating theme in the mouse position.

(6) Double click left or right sizing handles to remove extra horizontal spaces Double click up or down sizing handles to remove extra vertical spaces

(7) For the theme can add "Notes", press "F3" or the "Notes" button can add text or image on the theme of the note.

(8) Can be enlarged or reduced maps "=" or "-" on the keyboard.

(9) "Roll Down" or "Roll Up" will be a mind map can be used to a "Topic" under compression or local branches.

(10) Can choose a certain area, click the right mouse button with the "Print area" will Print the area, or choose a topic, click the right mouse button to choose the Division "Print", only Print the branch of the topics below.

\section{Teaching Process on Mind Map}

Mind map can make students better understand and memory readings focus on key words, the core concept and the hierarchical structure, highlight the main content and context of the article, the article structure is clear, students can understand the article efficiently; Reading motivation decided to reading effect, mind mapping helps to stimulate the students' reading motivation, use visual graphics rendering the main clues, reading materials fully start students imagination; Make and use mind mapping can develop the students' ability of information organization, the process of understanding context and structure of the article, constantly adding their own thinking and opinions, make students information organization ability get exercise, thus improve the reading ability. Mind map college English reading teaching process as follows [5, 6]:

(1) Preparation before class. About new content of mind mapping framework, teachers' learning tasks, students use a mind map preview. For teachers, mainly is to use mind mapping aided teaching design. In the process of preparing, access to relevant data and peer actively explore the teaching goal and teaching key, guiding, record, sorting and summing up the main content, open teaching idea, teaching design and teaching courseware, to prepare for classroom teaching. For students, mainly using mind mapping aided preview. In the finishing process of new knowledge, mind map to clearly show the relationship between the old and new knowledge, promote students to prepare 
effectively. In independent thinking and understanding of the reading at the same time, the use of mind mapping from discourse theme, structure, content, discourse heavy difficulty and language difficulties, etc., sort out and organize their own cognitive and doubt, a preliminary deal with reading materials, clear the content and need to have a deep understanding of the content, take a problem into classroom learning, effectively improve the efficiency of classroom learning.

(2) Class teaching. In the process of reading teaching, students have to listen to the teacher with a preview of doubt, and use mind map to remember your class notes. Through the answer questions, group discussion, teachers and classroom practice and verify the understanding of the article is correct, to absorb all the knowledge and key. First of all, teachers should in mind mapping graph based, to discuss with the student mind maps, guides the student to own a mind map to perfect, which not only can make the students to learn knowledge to consolidate, can further stimulate interest in learning; And then, the teacher guides the student to read prepared according to the content, into the deeper levels of reading content. After a quick scan, and guide students in the form of group discussion, quick sketch mind mapping of the article to understand. This link can make students in mind, mind maps provide knowledge interaction between information and articles, step by step to establish the content of the mind map or point of view, in order to post title as a starting point, on the basis of the content of each section to produce a mind map, and marking key parts, the final mind map; Finally, the teacher guides the student to further communication and study, constantly ask questions and find out the solution, to push deeper reading content and divergence, until finish the full mind map drawing.

(3) Consolidate after class. For teachers, mind mapping class teaching reflection, summative assessment tools and tool for teaching and scientific research. At the end of the class teaching, the teacher according to the actual situation of teaching, to reflect, change and design teaching again. Perfect the mind map constantly. Teachers use a mind map as a summative evaluation tool for students. Mind maps to present as a result of the in the mind of students about the knowledge structure of visual representation, help teachers understand students' mastery of reading materials. Teachers can also use a mind map analysis of the factors involved in reading teaching and learning, summarizes the teaching experience, the research on the rules of reading teaching activities, to lay the foundation for better reading teaching; Mind mapping is for students after class of learning tools, and summarizes the review tool. By the end of the classroom teaching, students use had built a good mind map, reflection and review the teaching contents, emphasis and difficulty. Through a reflection on the mind map, modify, and then design, gradually learn to reflect on their own learning process, improve learning efficiency and quality.

\section{Conclusion}

Mind map college English reading teaching has the following advantages: basic center, primary and secondary distinct, open development. Topic primarily, other information as a branch, from central graphics to radiation, the trunk can be increased, each branch can grow unceasingly, is conducive to the relationship between the elements of systems thinking; Theme clear, closely linked, easy to remember. Branch is composed of a key graphics or keyword, is not important topics in the form of branch, attached to a high level of form. Each branch line on keywords as a compass to comb and organizing thoughts connect structure. Easy to connect and dismiss and grasp the relationship. Each branch forms a connection structure, easy to grasp the connection and relationship of each branch used in work and life involved in learning and thinking activities. As a learning management, can develop a plan of study, communication, analysis and solve the problem.

\section{References}

[1] K. Wen, "The construction classification," Journal of Hotan Teachers College, vol. 30, no. 1, pp. 130-131, 2011.

[2] E. Y. Zhang, "The basic characteristics of mind map," 
http://book.51cto.com/art/201111/304037.htm, 2016-6-28.

[3] Baidu Experience, "Installation tutorial of MindMapper," http://jingyan.baidu.com/article/adc8151379f4e0f723bf7311.html, 2016-6-28.

[4] Small software talent, "How to install MindMapper mind map," http://mt.sohu.com/20151111/n426045162.shtml, 2016-6-28.

[5] J. H. Ning, L. J. Miao, "The practice of mind map in College English reading teaching," Education and Teaching Research, vol. 29, no. 12, pp. 75-78, 2015.

[6] C. S. Wang, G. Zhang, X. T. Wei, "The application of mind map in the teaching of College english reading," College English (Academic Edition), vol. 12, no. 2, pp. 17-19, 2015. 